\title{
Resistência de aderência de revestimentos de argamassa - contribuição por meio de mapeamento e revisão sistemática de literatura para futuras pesquisas no tema
}

\section{(Bond strength of renderings - contribution through mapping and systematic literature review for future research on the subject)}

\author{
F.H.B. Vaz ${ }^{1 *}$, H. Carasek ${ }^{1}$ \\ ${ }^{1}$ Universidade Federal de Goiás, Escola de Engenharia Civil e Ambiental, Programa de Pós-Graduação em \\ Geotecnia, Estruturas e Construção Civil, Goiânia, GO, Brasil
}

\begin{abstract}
Resumo
A resistência de aderência é uma das principais propriedades dos revestimentos de argamassa e é bastante estudada pelo meio científico. Essa propriedade tem uma gama de intervenientes que são normalmente tratados de maneira isolada nos trabalhos científicos. O presente trabalho visou contribuir com o domínio e relações da propriedade resistência de aderência, compilando e classificando trabalhos da literatura pelas variáveis utilizadas em seus estudos, servindo como embasamento para nortear futuras pesquisas. Para tanto, foi realizada uma revisão sistemática da literatura reunindo análises e comparações entre estudos (artigos) nacionais e internacionais que abordaram essa propriedade e seus fatores intervenientes. Um resultado interessante foi a compilação das performances dos aditivos e adições, em termos de variações médias, na resistência de aderência bem como correlações matemáticas com outras propriedades dos revestimentos.

Palavras-chave: revestimento, argamassa, resistência de aderência, revisão sistemática de literatura.
\end{abstract}

Abstract

The bond strength is one of the main properties of the renderings and largely studied by the scientific community. This property has a range of intervening factors that are usually treated separately in scientific papers. This work aimed to contribute to the domain and relations of bond strength property, compiling and classifying literature by the variables used in their studies, serving as a foundation to guide future research. Therefore, a systematic literature review was carried out, gathering analyzes and comparisons between national and international studies (papers) that approached this property and its intervening factors. An interesting result was the compilation of the performances of the admixtures and additions in terms of average variations in the bond strength as well as mathematical correlations with other properties of the renderings.

Keywords: render, mortar, bond strength, systematic literature review.

\section{INTRODUÇÃO}

Aderência é a propriedade do revestimento de resistir às tensões atuantes na interface com o substrato. Não se trata, portanto, de uma propriedade da argamassa, mas é a interação entre as camadas do sistema de revestimento [1]. Por sua vez, a resistência de aderência à tração, de acordo com a norma europeia EN 1015-12 [2], é determinada como a máxima tensão aplicada por uma carga direta perpendicular a um revestimento de argamassa em um substrato. Segundo a norma norteamericana ASTM D4541 [3], a medida dessa resistência de aderência depende tanto de parâmetros do material quanto do equipamento utilizado para a medição. Esta norma apresenta cinco aparelhos e suas particularidades,

*fhbv_@hotmail.com

(D) https://orcid.org/0000-0001-9477-2594 sendo a normativa mais completa desse ponto de vista. A aderência de revestimentos já vem sendo estudada, com maior enfoque, desde o final da década de 60 e início da década de 70 , quando existiu um grande esforço científico em entender essa propriedade, com o marco normativo da NBN 813-05 [4] que prescrevia o ensaio de aderência por 'arrancamento' (pull-off).

Uma revisão sistemática da literatura é a identificação, avaliação e interpretação de todas pesquisas disponíveis relevantes a uma questão de pesquisa ou área [5]. A maioria das revisões de literatura convencionais, ou informais, conforme [6], é aleatória, gerando pesquisas de pequeno valor científico. Ao agregar mais profundidade e objetividade, revisões sistemáticas demandam um esforço maior do pesquisador [7]. Neste sentido, uma análise sistemática da literatura disponível em periódicos e anais de congressos e simpósios foi realizada visando organizar e discutir os estudos publicados na área e os 
principais fatores que influenciam esta propriedade.

\section{MÉTODO}

Em [8], os autores discorrem acerca do método necessário ao desenvolvimento de uma revisão sistemática que faz parte de uma macroetapa chamada de 'condução da revisão' conforme proposta em [9], que se trata de delimitar os bancos de dados (fontes), delimitar a pesquisa e propor critérios de seleção de modo a focar o levantamento. As bases de dados, tanto internacionais quanto nacionais, foram escolhidas de acordo com a afinidade com a área de pesquisa, de modo a melhor entender a relevância e identificar as lacunas do conhecimento no tema. Assim, Infohab, Scielo, Engineering Village (Compendex), Science Direct, Scopus e Web of Science foram os bancos de dados selecionados. Estas bases retornaram basicamente artigos científicos publicados em periódicos e eventos científicos. Isto foi considerado um parâmetro aceitável, pois assim os artigos dos periódicos considerados aderentes puderam ter seus fatores de impacto, ou seja, suas relevâncias científicas mensuradas.

Para guiar a construção da string de busca, foi necessário variar não somente a sintaxe concreta da pesquisa, mas também os termos de pesquisa necessários, de forma semelhante ao apresentado em [7], uma vez que existem diversos termos e contextos que se inserem no escopo da pesquisa, ou seja, são aderentes ao objetivo da pesquisa. Portanto, foram escolhidos termos que conseguissem englobar os trabalhos relevantes, mas evitando um grande volume de trabalhos irrelevantes. Após os ajustes necessários, tomando por base ainda as estratégias de construção de termos de busca elencadas em [5], foi definida a seguinte string: (adhe* OR bond*) AND (strength) AND (mortar) AND (render* OR coat* OR plaster*) AND (cement OR lime) AND NOT (tiles OR repair mortar). Nota-se que foram utilizados prefixos de termos ligados pelo operador booleano 'ou', pois existem diferentes palavras em inglês para um mesmo conceito em português que atendem à pesquisa. Os termos referentes às placas cerâmicas (tiles) e argamassa de reparo (repair mortar) foram retirados das buscas, pois não condizem com o objetivo do trabalho. Para as bases Infohab e Scielo, foi usada uma string também em português: 'resistência de aderência'.

A etapa de seleção dos artigos passou por dois processos: no primeiro analisaram-se as afinidades do título e do resumo com as questões da pesquisa, sendo considerados apenas os artigos em português e inglês, desprezando-se os trabalhos em outras línguas. Dentre os artigos selecionados, no segundo momento, todo o artigo foi estudado para atestar sua relevância para esta pesquisa, conforme proposto em [6]. Os critérios de inclusão (seleção) foram: artigos que identificaram os substratos e os revestimentos estudados, que descreveram os fatores que influenciaram ou não a resistência de aderência à tração, e que apresentassem, se possível, os resultados obtidos nos procedimentos e versassem sobre as normas utilizadas para os ensaios. Como critérios de exclusão foram adotados: artigos em duplicidade nos bancos de dados, que não atendessem aos critérios de seleção, que tratassem de resistência de aderência de revestimentos cerâmicos ou que utilizaram argamassas compostas de gesso ou de reparo estrutural. Trabalhos que abordaram questões totalmente ligadas a concreto e a revestimentos de pavimentos também foram excluídos do levantamento. Por fim, a técnica de bola de neve (snow balling technique) foi utilizada para identificar outros artigos relevantes, conforme preconizado em [6]. Tratou-se de identificar novos artigos relevantes a partir de uma análise das referências dos artigos já identificados e selecionados, melhorando ainda mais a revisão sistemática da literatura. A pesquisa da revisão sistemática foi realizada inicialmente entre janeiro e fevereiro de 2017 e atualizada em dezembro de 2017. Foi ainda revisada em março de 2018, a fim de englobar artigos publicados no último Simpósio Brasileiro de Tecnologia das Argamassas (SBTA), incluídos na base Infohab.

\section{RESULTADOS E DISCUSSÃO}

Os principais resultados da aplicação do método apresentado anteriormente foram divididos em mapeamento sistemático, onde há uma visão macro dos

Tabela I - Distribuição dos artigos por base de dados.

[Table I - Distribution of articles by database.]

\begin{tabular}{cccc}
\hline \multirow{2}{*}{ Base de dados } & $\begin{array}{c}\text { Total de publicações } \\
\text { iniciais }\end{array}$ & \multicolumn{2}{c}{ No. artigos selecionados } \\
& 248 & 70 & 58 \\
Infohab & 99 & 18 & 11 \\
SciELO & 73 & 11 & 5 \\
Engineering Village & 3148 & 71 & 12 \\
Science Direct & 1274 & 62 & 10 \\
Scopus & 70 & 19 & 2 \\
Web of Science & & & $2^{\circ}$ processo de seleção \\
\hline
\end{tabular}


artigos selecionados, e levantamento das pesquisas, onde há uma análise detalhada destes artigos.

Mapeamento sistemático: após aplicação dos procedimentos mencionados e busca nos bancos de dados, foram encontrados inicialmente 4912 artigos dentre os quais 4565 foram oriundos das bases internacionais e 347 artigos foram obtidos nas plataformas nacionais, Infohab e Scielo. Com 7\% do total, as bases nacionais ainda compreenderam pequena quantidade de pesquisas mais relevantes sobre o tema, muito embora tenha sido detectada crescente melhora ao longo dos últimos três anos. A Tabela I apresenta as frequências destas publicações por origem dos artigos e por processo de seleção (explicitados no item Método). Nela é possível notar que, no contexto da busca, o aproveitamento das bases internacionais foi muito pequeno enquanto que na base nacional um maior percentual de publicações aderentes foi encontrado. Engineering Village e Scopus foram os bancos de dados com as maiores quantidades de retornos iniciais, muito embora o aproveitamento tenha sido pequeno em ambos.

Na Tabela II é possível acompanhar as etapas de seleção dos artigos. Ao final, 102 trabalhos foram considerados relevantes ou aderentes. O primeiro processo de seleção foi o responsável pelo maior percentual de exclusão: quase $96 \%$ dos artigos encontrados pela string não foram significativos para a presente pesquisa; por algum motivo desconhecido as bases internacionais retornaram muitos trabalhos irrelevantes. Tendo como critério os artigos em periódicos e eventos de tecnologia das argamassas, conforme verificado pelo número pequeno de publicações consideradas aderentes, embora sejam muito relevantes, notou-se que a comunidade internacional ainda vem publicando timidamente estudos na área específica.

Tabela II - Etapas de seleção dos artigos.

[Table II - Stages of selection of articles.]

\begin{tabular}{cc}
\hline Etapa & $\begin{array}{c}\text { No. } \\
\text { artigos }\end{array}$ \\
\hline $\begin{array}{c}\text { Seleção nas bases de dados } \\
\text { mediante string de busca }\end{array}$ & 4912 \\
Primeiro processo de seleção & \\
(por meio dos títulos e resumos) & -4685 \\
$\quad$ Trabalho em duplicidade & -51 \\
Artigo sem texto completo disponível & -38 \\
$\quad \begin{array}{c}\text { Segundo processo de seleção } \\
\text { (por meio da leitura dos artigos) }\end{array}$ & -40 \\
Amostragem pela técnica de bola de neve & +4 \\
$\quad \begin{array}{c}\text { Total de trabalhos considerados } \\
\text { relevantes nesta pesquisa }\end{array}$ & 102 \\
\hline
\end{tabular}

Uma importante ação é verificar os fatores de impacto dos periódicos cujas publicações internacionais selecionadas foram publicadas. Para isto, foi avaliado o indicador SCImago Journal Rank (SJR), reconhecido internacionalmente, tendo como referência o ano de publicação. O indicador, conforme [10], expressa o número médio das citações recebidas no ano de referência ponderadas pelos documentos publicados no referido periódico nos três anos anteriores. Foi possível notar que os trabalhos aderentes, das bases pesquisadas, foram encontrados em 22 periódicos. O periódico Construction and Building Materials (SJR 1,49 em 2017) foi o meio de publicação com a maioria dos artigos selecionados nesse mapeamento sistemático de literatura, com um total de 14 trabalhos publicados ao longo dos anos, sendo que em 2012 e 2016 foram dois artigos e em 2015 três artigos publicados. O periódico Cement and Concrete Composites, no qual foi publicado um artigo sobre o tema estudado, apresentou o maior fator de impacto SJR $(3,118$ em 2014); salienta-se que esse periódico ocupa o $2^{\circ}$ lugar no ranking do SJR na área Engineering-Building and Construction [10]. As duas melhores revistas nacionais classificadas e que tiveram artigos selecionados foram: Polímeros (SJR 0,24 em 2012) e Cerâmica (SJR 0,206 em 2014).

Levantamento das pesquisas: as publicações possuem abordagens diferentes a respeito da resistência de aderência à tração, seja discutindo o ensaio e seus resultados ou versando sobre fatores que influenciam na resistência de aderência. Inicialmente foi proposta a Tabela III, que apresenta uma classificação principal dos trabalhos relevantes ao tema selecionado trazendo uma melhor compreensão das suas abordagens; notouse que alguns trabalhos que abordam os ensaios também estudam influências entre parâmetros ou a relação da resistência de aderência com outras propriedades. Ainda sobre a Tabela III, é possível notar que as principais

Tabela III - Compilação dos artigos aderentes, separados por metodologia de ensaio adotada para determinação da resistência de aderência à tração.

[Table III - Compilation of adherent articles, separated by test methodology adopted to determine the bond strength.]

\begin{tabular}{cccc}
\hline Norma/método & Ano & Total & Ref. \\
\hline ASTM D4541 (EUA) & 2009 & 1 & {$[11]$} \\
ASTM D7234 (EUA) & 2005 & 2 & {$[12,13]$} \\
CE-02:002.17-003 (Brasil) & 1995 & 5 & {$[14-18]$} \\
EN 1015-12 (União & 2000 & 12 & {$[19-30]$} \\
Europeia) & 2005 & 4 & {$[31-34]$} \\
NBR 13528 (Brasil) & 1995 & 28 & {$[35-62]$} \\
NBR 15258 (Brasil) & 2010 & 19 & {$[63-81]$} \\
NC 172 (Cuba) & 2005 & 6 & {$[82-87]$} \\
Próprio/adaptado & & 2 & {$[88,89]$} \\
Sem referência do método utilizado & 3 & {$[90-95]$} \\
Estudo de influências ou de literatura & 14 & {$[99-112]$} \\
\hline
\end{tabular}


normas utilizadas são as brasileiras e europeias. A norma cubana NC 172 [113] também foi utilizada em dois trabalhos bem como as normas americanas ASTM D7234 [114] e ASTM D4541 [3], esta última citada em duas publicações $[106,110]$ somente como referência.

$\mathrm{Na}$ Tabela IV, baseada na desenvolvida em [103], seguem dados atualizados das três normativas mais presentes nos trabalhos que compuseram esta revisão sistemática. Um ponto interessante é que na maioria das normativas e padronizações de ensaios os resultados são apresentados pelos valores individuais de tensão na ruptura encontrados e não médios, a exemplo das normas brasileira e europeia. Embora não seja considerada uma norma técnica de um país, a International Union of Laboratories and Experts in Construction Materials, Systems and Structures (RILEM) publicou a recomendação MDT.D.3 [116], baseada na EN 101512 [2], que é utilizada por alguns autores, pois traz o procedimento de ensaio de resistência de aderência à tração realizado em campo e para revestimentos históricos. Esta recomendação foi citada por alguns autores $[106,110]$ nos trabalhos pesquisados.

Para organizar as análises, primeiramente são apresentados os principais resultados, no que diz respeito à aderência à tração, de um artigo encontrado durante a pesquisa que também trata de uma revisão sistemática, desta feita sobre uso de agregados reciclados em argamassas. Posteriormente, são apresentadas as análises sobre as variáveis adotadas pelos autores das literaturas estudadas, a saber: tipos de substratos, tipos/composição das argamassas de revestimento, características da execução dos revestimentos e relativas aos ensaios de aderência.

Paralelo com outra revisão sistemática de literatura: foi considerado aderente à presente pesquisa o trabalho [111], que trata de uma revisão sistemática da literatura sobre o uso de agregados reciclados nos revestimentos de argamassa. No que cerne à análise de resistência de aderência, em testes análogos aos discorridos neste artigo e alvo desta sistematização, os autores notaram que em geral a adição de agregados reciclados melhorou ou ao menos não influenciou a resistência de aderência

Tabela IV - Principais características de diferentes métodos de ensaio de resistência de aderência à tração.

[Table IV - Main characteristics of different test methods of bond strength.]

\begin{tabular}{|c|c|c|c|}
\hline & ABNT NBR 13528 [1] & ABNT NBR 15258 [115] & EN 1015-12 [2] \\
\hline $\mathrm{N}^{\circ}$ de $\mathrm{CPs}$ & $\geq 12$ & $\geq 10$ & $\geq 5$ \\
\hline Aplicação & Obra e laboratório & Laboratório & Laboratório \\
\hline Substrato padrão & - & $\begin{array}{l}\text { Conforme NBR } 14082 \\
\text { (recomenda-se pigmentado) }\end{array}$ & $550 \times 150 \times 50 \mathrm{~mm}$ \\
\hline Condições do substrato & Vertical/horizontal e limpo & Nivelado e limpo & Nivelado \\
\hline Forma e seção do CP & Circular, diâmetro $=50 \mathrm{~mm}$ & Circular, diâmetro $=50 \mathrm{~mm}$ & $\begin{array}{c}\text { Circular, } \\
\text { diâmetro }=50 \pm 0,1 \mathrm{~mm}\end{array}$ \\
\hline Espessura da pastilha & Mínimo de $10 \mathrm{~mm}$ & Mínimo de $5 \mathrm{~mm}$ & Mínimo de $10 \mathrm{~mm}$ \\
\hline Tipo de corte & Argamassa endurecida & Argamassa endurecida & $\begin{array}{l}\text { Argamassa fresca ou } \\
\text { endurecida }\end{array}$ \\
\hline Profundidade do corte & Mínimo até substrato & $1 \mathrm{~mm}$ dentro do substrato & $\begin{array}{l}2 \mathrm{~mm} \text { dentro do } \\
\text { substrato }\end{array}$ \\
\hline $\begin{array}{c}\text { Condições de cura da } \\
\text { argamassa }\end{array}$ & - & $\begin{array}{c}\geq 1 \mathrm{dia}, \mathrm{T}=23 \pm 2{ }^{\circ} \mathrm{C} \\
\mathrm{UR}=60 \% \pm 5 \%\end{array}$ & $\begin{array}{c}\geq 21 \text { dias, } \mathrm{T}=21 \pm 2{ }^{\circ} \mathrm{C} \\
\mathrm{UR}=65 \% \pm 5 \%\end{array}$ \\
\hline Distância entre CPs & $\begin{array}{l}\text { Distância entre CPs, dos } \\
\text { cantos e quinas de no } \\
\text { mínimo } 50 \mathrm{~mm}\end{array}$ & $\begin{array}{l}\text { Distância entre CPs no } \\
\text { mínimo de } 20 \mathrm{~mm} \text { e dos } \\
\text { cantos e quinas de no } \\
\text { mínimo } 40 \mathrm{~mm}\end{array}$ & - \\
\hline Tipo de cola & $\begin{array}{l}\text { Recomenda epóxi, poliéster } \\
\text { ou similar }\end{array}$ & Base de resina epóxi & $\begin{array}{l}\text { Base de resina (epóxi ou } \\
\text { metilmetacrilato) }\end{array}$ \\
\hline Equipamento de tração & $\begin{array}{l}\text { Dinamômetro de tração, } \\
\text { baixo peso, erro máximo de } \\
2 \%\end{array}$ & $\begin{array}{l}\text { Articulado para assegurar o } \\
\text { esforço de tração simples, } \\
\text { erro máximo de } 2 \%\end{array}$ & Não especificado \\
\hline $\begin{array}{l}\text { Condição de aplicação } \\
\text { do carregamento }\end{array}$ & Constante até a ruptura & $\begin{array}{l}\text { Aplicação contínua de carga } \\
\qquad 250 \pm 50 \mathrm{~N} / \mathrm{s}\end{array}$ & $\begin{array}{c}\text { Sem choque e uniforme, } \\
0,003 \text { a } 0,1 \mathrm{~N} /\left(\mathrm{mm}^{2} . \mathrm{s}\right)\end{array}$ \\
\hline $\begin{array}{l}\text { Apresentação dos } \\
\text { resultados }\end{array}$ & $\begin{array}{l}\text { Valores individuais de } \\
\text { tensão, em MPa }\end{array}$ & $\begin{array}{l}\text { Valores individuais de } \\
\text { tensão, em MPa }\end{array}$ & $\begin{array}{l}\text { Valores individuais de } \\
\text { tensão, em N/mm² }\end{array}$ \\
\hline
\end{tabular}


dos revestimentos quando comparados a revestimentos de argamassas elaboradas com agregados naturais (argamassas de referência). Ainda foi discutido no estudo citado [111] que o uso de agregado reciclado muito fino em substituição parcial à areia natural possibilitou a redução no consumo de cimento de $20 \%$ a $33 \%$ para obtenção do mesmo desempenho.

Características dos substratos: refletindo a ampla diversidade de bases para os revestimentos de argamassa, nos artigos selecionados foram utilizados diversos tipos de substrato, como demonstrado na Fig. 1. As alvenarias de blocos cerâmicos [14-16, 35, 36, 38, 39, 42, 43, 48, 50, 54$57,61-63,66,69,70,74,75,77,80,90,97,105-108,110]$ e os corpos de prova individuais sobre blocos cerâmicos $[18-29,34,40,51,52,60,65,71,73,78,79,93,98,101$, 109] foram os substratos mais empregados nas pesquisas encontradas, seguidos de estruturas de concreto $[12,13,17$, $40,41,45,49,58,62,63,67,76,78,82,94,106,110]$, alvenarias de blocos de concreto [14, 30, 37, 44, 46, 47, 55, 59, 62-64, 81, 89, 106-108], substratos-padrão [64, 83, 85, $86,92,95,102,112]$, blocos individuais de concreto [17, $40,53,78,84,88,109]$, alvenaria de/ou blocos de concreto celular autoclavado $[14,40]$, alvenaria de/ou blocos sílicocalcário $[14,40]$ e granito [91].

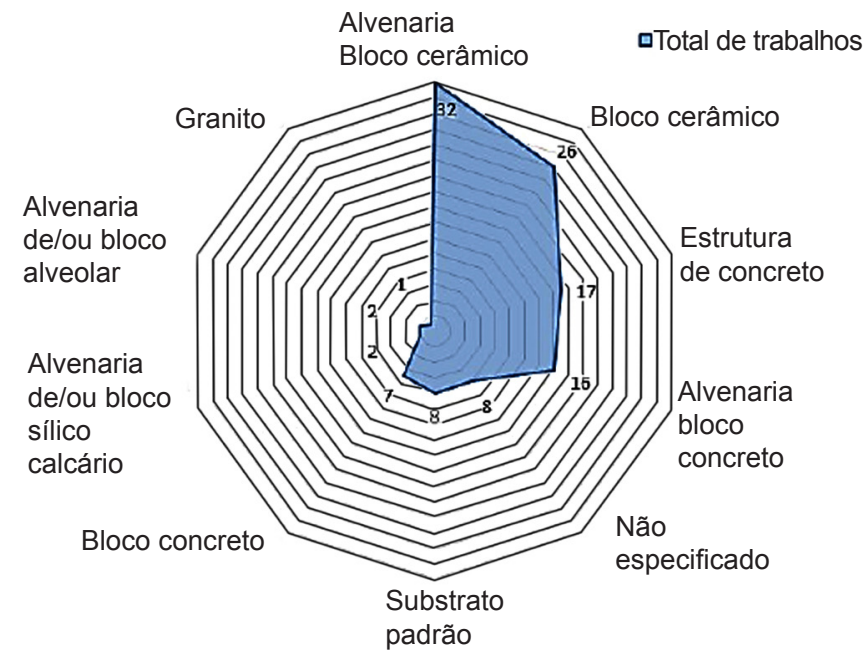

Figura 1: Tipos de substratos utilizados nas pesquisas encontradas nos artigos aderentes.

[Figure 1: Types of substrates used in researches found in adherent articles.]

No trabalho [109], com testes em laboratório em bases formadas por blocos individuais cerâmicos e de concreto, fixando as demais variáveis, identificou-se que nos substratos de blocos de concreto chegou-se a uma média de 0,36 MPa na resistência de aderência, enquanto que nos blocos cerâmicos a média foi de $0,17 \mathrm{MPa}$, quase $52 \%$ inferior. Nos estudos [108, 55], em alvenarias, com os revestimentos apresentando idade de 28 dias, os aplicados sobre as paredes de blocos de concreto apresentaram todas médias, em 21 painéis, acima de 0,30 $\mathrm{MPa}$ enquanto que nas construídas com blocos cerâmicos todas médias de aderência foram inferiores a 0,20 MPa. Resultados similares foram encontrados em [63], com ensaios em obra, onde também perceberam um valor $31 \%$ maior nos substratos de bloco de concreto. Portanto, vale estender esta constatação para casos em alvenaria visto que, do ponto de vista de aderência, os blocos, e não as juntas, são considerados a parte frágil do conjunto [103, 117]. Alguns trabalhos [35, 36, 42, 43, 90] analisaram a influência nos resultados de aderência do local de realização do ensaio nas alvenarias, seja quando o revestimento está aplicado sobre a junta de assentamento, seja sobre os blocos. Nestes trabalhos, chegou-se à conclusão de que as resistências sobre as juntas foram consideravelmente maiores que as encontradas sobre os blocos; em [35, 36], verificouse serem $75 \%$ e $60 \%$ superiores, respectivamente. Em função desta constatação nas pesquisas, foi introduzido na atual metodologia de ensaio de aderência prescrita pela ABNT [1] o seguinte texto: "Em alvenarias, de blocos cerâmicos, concreto, dentre outros, os corpos de prova devem ser posicionados preferencialmente sobre os blocos, a favor da segurança, visto que os corpos de prova de revestimento ensaiados sobre as juntas de assentamento geralmente apresentam maiores valores de aderência". De maneira mais abrangente, em [62] encontrou-se por substrato, em ordem decrescente de resistências de aderência: laje de concreto 0,27 MPa de média; alvenaria de bloco de concreto celular $0,17 \mathrm{MPa}$ de média; alvenaria de bloco de concreto 0,16 MPa de média; e alvenaria de bloco cerâmico 0,14 MPa de média. Concomitante com o que se extrai de [99], é possível dizer que o tipo de substrato exerce grande influência nas resistências de aderência dos revestimentos de argamassa.

Tipos de tratamentos dos substratos: permanecendo na análise da influência do substrato, alguns autores optaram por utilizar algum tipo de mecanismo para melhorar a aderência das argamassas a este, espécies de 'pontes de aderência', tais como: chapisco [14-18, 35-39, 41, 45, 47, 49, 50, 53-59, 61-63, 66, 67, 69, 70, 73, 74, 77, 78, $82,87,90,97,105,107,108]$, superfície do substrato texturizada (com sulcos) $[67,76,112]$, umedecida [16, $23,26,40,42,52,53,55,74]$ e solução de cal $[54,55$, $74,90]$. Alguns trabalhos [16, 54, 55, 77] demonstraram que superfícies preparadas com chapisco apresentaram resistência de aderência até cerca de $30 \%$ maior do que em substratos sem preparo. De modo amplo, nas pesquisas [14, 17], também é possível notar uma melhora na aderência com a aplicação do chapisco. Nesse último estudo citado, o uso de solução de cal na alvenaria de blocos cerâmicos apresentou resultados $35 \%$ maiores do que a alvenaria sem preparo. Outro estudo [107] também demonstrou notável melhora da aderência com o uso de chapisco. Angelim [90] mostrou que o uso de solução de cal no preparo da base melhorou em $38 \%$ a aderência em relação ao uso de chapisco. Os autores em [74] administraram solução de cal sobre o chapisco 
(média de 0,24 MPa) em comparação com o chapisco umedecido apenas com água (média de 0,18 $\mathrm{MPa}$ ) e obtiveram valores estatisticamente parecidos levandose em conta os respectivos desvios padrões. Outro estudo [42] também obteve valores parecidos quando se contrasta um substrato seco com um umedecido (ambos sem chapisco). Carasek [40] concluiu que o teor de umidade dos substratos, no momento da aplicação, é geralmente inversamente proporcional à resistência de aderência do revestimento de argamassa. Moura et al. [49] salientaram que revestimentos sobre chapiscos convencionais apresentaram resistências de aderência menores que os revestimentos aplicados sobre chapiscos industrializados. Entretanto, os autores informaram que este comportamento pode ter sido devido ao maior teor de cimento de um dos chapiscos industrializados utilizados naquela pesquisa. Já no estudo [67], os autores obtiveram resultados similares, porém atribuíram o motivo ao fato de que os chapiscos industrializados possuem aditivos com propriedades adesivas em sua composição. No trabalho [97] foi percebida uma melhora significativa na aderência (32\% maior do que no revestimento de referência) quando adicionados 5\% de metacaulim em substituição ao cimento do chapisco convencional.

De acordo com [76, 112], em uma superfície rugosa (texturizada), os revestimentos apresentaram valores médios de resistência de aderência cerca de $10 \%$ e $14 \%$ superiores que em uma superfície lisa, respectivamente. No entanto, em [67], após escovar e apicoar a superfície do substrato, foi atingida média de $0,36 \mathrm{MPa}$ frente aos 0,45 $\mathrm{MPa}$ quando sem tratamento algum; o fato foi explicado pelo efeito combinado com os tipos de chapisco empregados (no caso de chapisco industrializado, por exemplo, que advém de uma aderência química, a aderência, segundo os autores, foi prejudicada em superfícies mais irregulares). No trabalho [77] percebeu-se que para o mesmo tipo de material do substrato (blocos cerâmicos), a textura da superfície contribuiu para a melhora da aderência do revestimento em todas situações analisadas, chegando a valores até $37,5 \%$ maiores nos substratos de blocos nervurados quando comparados com os lisos. Macedo et al. [45] alertaram para a tendência de queda de resistência com a demora na execução do revestimento após aplicação de chapisco rolado. No estudo [78] utilizando chapisco industrializado (rolado), os substratos de blocos cerâmicos e de concreto apresentaram a mesma média global (0,52 MPa), muito embora nos blocos de concreto tenha-se alcançado $0,71 \mathrm{MPa}$ com um dos revestimentos trabalhados, e uma média global de 0,33 $\mathrm{MPa}$ quando o substrato foi o concreto estrutural. Em [58] os pesquisadores concluíram que "a utilização da sílica extraída da casca de arroz, em teores de 5\% nos chapiscos e pastas, propicia ganhos significativos de resistência de aderência e possibilita executar chapiscos com uma compacidade mais adequada, permitindo ligações mais efetivas com substratos de concreto".
Por todo este exposto a respeito do preparo e tratamento da base e conforme descrito em [99], devese promover algum tipo de tratamento superficial do substrato com finalidade de regularizar e homogeneizar a capacidade de sucção de água ou aumentar a rugosidade superficial para que, com isso, haja um aumento na capacidade aderente da base.

Características das argamassas de revestimento: nos trabalhos revisados, foram levantados também as propriedades das argamassas no estado endurecido que foram determinadas pelos autores das pesquisas sobre aderência. Os quantitativos (Fig. 2) demonstraram que a resistência à compressão axial foi a propriedade mais estudada/correlacionada (62 trabalhos) seguida da resistência à tração na flexão (41 trabalhos). No que diz respeito às argamassas utilizadas como revestimentos, uma das informações importantes é o traço utilizado. A Tabela V apresenta os proporcionamentos (traços), em volume, das argamassas utilizadas. Em [90] foram descritos resultados que mostram que revestimentos de argamassa industrializada apresentaram valores médios de resistência de aderência menores que os obtidos com argamassa mista. No entanto, em contraposição, os resultados encontrados em pesquisa realizada em obra contendo 2465 ensaios válidos, as argamassas industrializadas alcançaram média muito superior às argamassas mistas preparadas também em obra de, respectivamente, 0,43 e 0,21 $\mathrm{MPa}$, valores esses obtidos sobre vários substratos [63]. Similarmente, em [53, $62,77]$ encontraram-se valores de aderência ao menos iguais ou superiores nos revestimentos de argamassa industrializada com relação aos de argamassa mista. Carasek [40] encontrou resistências de aderência para revestimentos com argamassa industrializada com valores 'intermediários' ao de duas mistas e uma simples; a explicação foi que em altos teores de cimento (em uma mista e na simples) a aderência foi maior, ou seja, onde

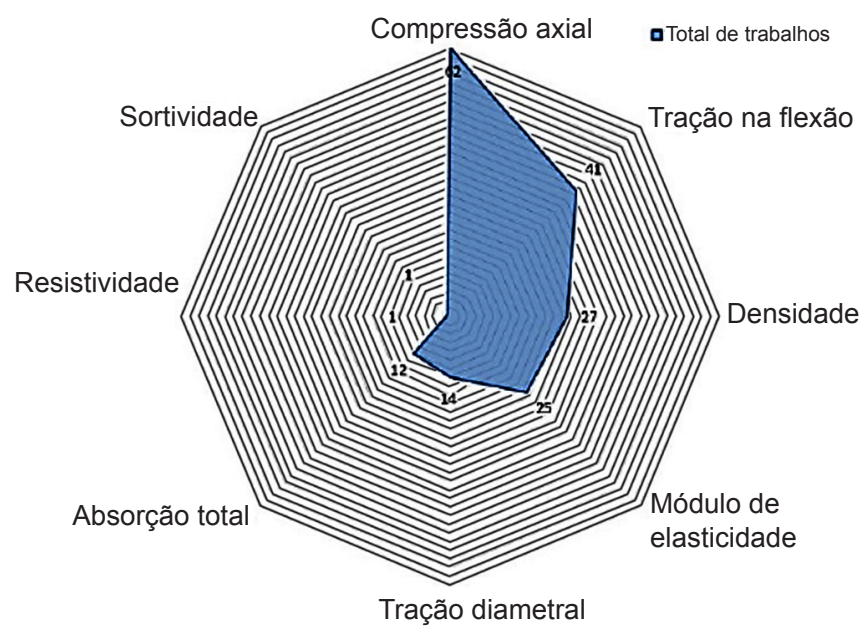

Figura 2: Propriedades das argamassas, no estado endurecido, determinadas nos artigos aderentes.

[Figure 2: Properties of mortars, in the hardened state, determined in the adherent articles.] 
Tabela V - Tipos de argamassa e traços (em volume) utilizados. [Table V - Types of mortar and proportions (by volume) used.]

\begin{tabular}{|c|c|}
\hline Traço & Ref. \\
\hline \multicolumn{2}{|c|}{ Cimento (simples) - cimento:agregado (18 artigos) } \\
\hline $1: 1,25$ & [33] \\
\hline $1: 2,5$ & {$[33]$} \\
\hline $1: 3$ & {$[34,40,80,93,101]$} \\
\hline $1: 3,24$ & [95] \\
\hline $1: 3,75$ & [33] \\
\hline $1: 3,8$ & {$[83,105]$} \\
\hline $1: 4$ & {$[19,22-25,28,29,88,89]$} \\
\hline $1: 4,3$ & {$[83,93]$} \\
\hline $1: 5$ & {$[16,24,79,88,89]$} \\
\hline $1: 5,88$ & [33] \\
\hline $1: 6$ & {$[47,59,69,87,89]$} \\
\hline $1: 6,5$ & [68] \\
\hline $1: 7,5$ & [93] \\
\hline $1: 8$ & [16] \\
\hline $1: 9$ & [45] \\
\hline $1: 10$ & {$[16]$} \\
\hline $1: 12$ & {$[16]$} \\
\hline \multicolumn{2}{|c|}{$60,65,70,74,84,85,91]^{*}$} \\
\hline \multicolumn{2}{|c|}{ Cal (simples) - cal:agregado (2 artigos) } \\
\hline $1: 6$ & {$[38,39]$} \\
\hline \multicolumn{2}{|r|}{$[20,21]^{*}$} \\
\hline \multicolumn{2}{|c|}{ Cimento e cal (mista) - cimento:cal:agregado (29 artigos } \\
\hline $1: 0,25: 3$ & [40] \\
\hline $1: 0,4: 5,7$ & {$[83]$} \\
\hline $1: 0,5: 1$ & [50] \\
\hline $1: 0,5: 3$ & [50] \\
\hline $1: 0,5: 5$ & [50] \\
\hline $1: 0,5: 6$ & [50] \\
\hline $1: 0,6: 8,7$ & [83] \\
\hline $1: 1: 4$ & {$[57,112]$} \\
\hline $1: 1: 5,5$ & {$[49]$} \\
\hline $1: 1: 6$ & {$[15,17,35,36,42,47,50,55-57,61,66$, } \\
\hline $1: 1: 6,5$ & [105] \\
\hline $1: 1: 8$ & {$[57,105]$} \\
\hline $1: 1: 9$ & {$[15]$} \\
\hline $1: 1,24: 6,82$ & [109] \\
\hline $1: 1,47: 6,82$ & [109] \\
\hline $1: 1,5: 6$ & [71] \\
\hline $1: 1,5: 9$ & {$[38,39]$} \\
\hline $1: 1,5: 4$ & [51] \\
\hline $1: 1,5: 7$ & [72] \\
\hline $1: 1,8: 6,7$ & [43] \\
\hline $1: 2: 4$ & [88] \\
\hline $1: 2: 6$ & {$[57,77]$} \\
\hline $1: 2: 8$ & {$[68,86]$} \\
\hline $1: 2: 9$ & {$[14,36,40,48,57,61]$} \\
\hline $1: 2: 12$ & [57] \\
\hline $1: 3: 8$ & [57] \\
\hline $1: 3: 12$ & [57] \\
\hline $1: 3: 16$ & [57] \\
\hline \multicolumn{2}{|c|}{$[16,18,30,32,37,41,46,53,58,62,64,76,98,106]^{*}$} \\
\hline$[14,40,41,4$ & $\begin{array}{l}\text { Industrializada (23 artigos) } \\
7,49,53,54,59,62,63,67,75,77,78,81 \text {, } \\
7,90,92,94,102,106-108]^{*}\end{array}$ \\
\hline
\end{tabular}

esse teor foi baixo, a resistência foi menor.

Seguindo nas análises, na Fig. 3 são apresentados os espectros de traços das argamassas simples de cimento e a flutuação dos coeficientes de variação $(\mathrm{CVs})$ dos resultados individuais de resistência de aderência dos trabalhos que forneceram ou nos quais foi possível calcular. Na Fig. 3 é possível observar que os traços das argamassas simples de cimento mais estudados variam entre 1:3 e 1:6. Houve uma tentativa na Fig. 3 de correlacionar o empobrecimento da argamassa, marcado pela diminuição do teor de cimento nas composições de argamassa, com o aumento da variabilidade (CV) dos resultados de resistência de aderência. Notou-se, após exclusão de três resultados espúrios (por meio de gráfico de controle), uma correlação linear aceitável $\left(R^{2}=0,6\right)$ mostrando que existe uma tendência do teste de aderência se tornar cada vez menos preciso, pelo aumento do $\mathrm{CV}$, à medida que a proporção de aglomerante diminui nas argamassas, ou seja, quando essas argamassas apresentam menor resistência mecânica.

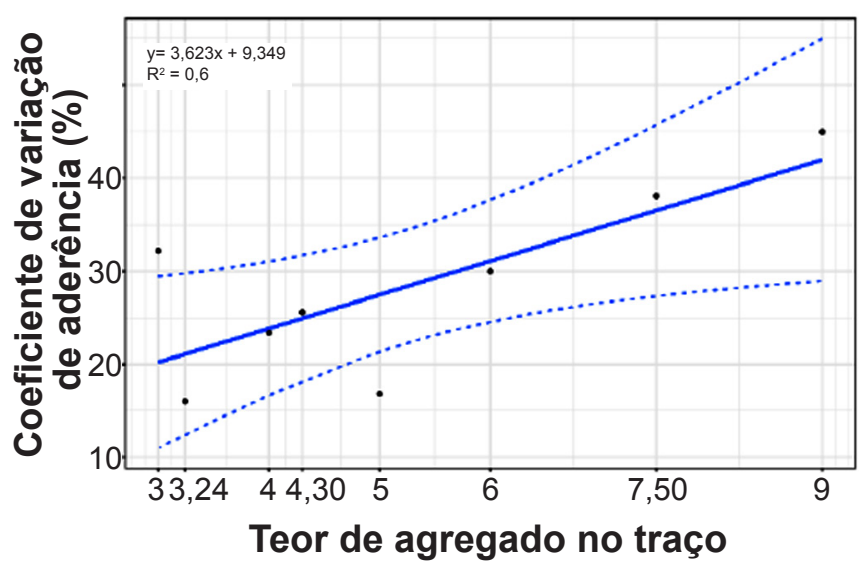

Figura 3: Proporções de agregados e coeficientes de variação médios dos resultados de resistência de aderência para as argamassas simples com base cimentícia.

[Figure 3: Proportions of aggregates and average coefficients of variation of bond strength results for cement-based simple mortars.]

Os constituintes mais utilizados nas composições das argamassas são: os aglomerantes, cimento (hidráulico) e cal (aéreo), e os agregados miúdos, sejam areias naturais ou artificiais muitas vezes oriundas de britagens e moagens de rochas e ou resíduos da construção. A Fig. 4 apresenta estes componentes convencionais das argamassas utilizados nas diversas pesquisas. Segundo [118], os cimentos europeus CEM I 42, CEM II/A-L 42.5R, CEM II/B-L 32.5 e CEM IV/B 42.5 são equivalentes aos cimentos brasileiros CP V-ARI, CP II F-40, CP II F-32 e CP IV-40, respectivamente. Em cinco artigos foram utilizadas cales virgens comuns (CV-C) que passaram por um processo preliminar de hidratação e maturação de sete dias antes da mistura para argamassa de revestimento. No tocante à variedade 
de cimentos e cales, em [37] estudaram-se diversas argamassas formuladas com vários tipos de cimento e dois tipos de cal. As argamassas compostas por cimento CP V-ARI obtiveram os maiores valores de aderência (0,60 MPa com a cal CH I e 0,80 MPa com CH III), já as formuladas com CP II F resultaram nos menores valores $(0,15$ e $0,30 \mathrm{MPa}$, respectivamente, para cal $\mathrm{CH}$ I e $\mathrm{CH}$ III). Ressaltou-se, na referida pesquisa, que o cimento CP III embora resultasse em baixos valores de aderência nas idades iniciais, apresentou crescimento contínuo de resistência até 182 dias, chegando próximo aos valores de aderência obtidos nas composições com CP V-ARI (que nesse caso alcançaram seu pico de resistência até os 63 dias). Outro estudo [99] ressalta que o parâmetro mais significativo é a finura do cimento; quanto mais fino o cimento, maior a aderência obtida. Quanto à cal, o teor de hidróxido de magnésio, conforme se depreende de [99], influencia diretamente a resistência de aderência, ou seja, as cales dolomíticas formam grandes cristais de carbonato de cálcio nas argamassas, retendo mais água, melhorando a aderência dos revestimentos.

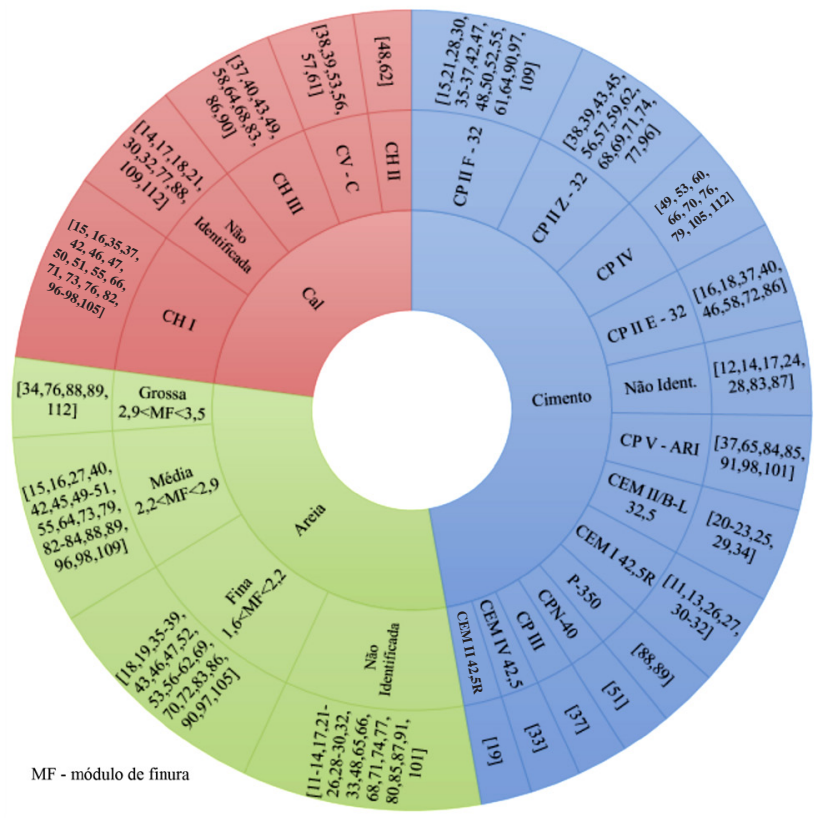

Figura 4: Aglomerantes e agregados miúdos utilizados nas pesquisas (por tipo de material).

[Figure 4: Binders and small aggregates used in the researches (by type of material).]

Na Fig. 4 as areias foram classificadas utilizando critério comum no meio técnico pelos módulos de finura, segundo a antiga norma NBR 7211 [119]. Isto porque a especificação do módulo é comum na grande maioria dos trabalhos analisados mesmo que tal classificação não esteja mais vigente na atual norma NBR 7211 [120]. Do ponto de vista da granulometria das areias utilizadas, dois estudos [66, 95] demonstraram que no geral os revestimentos com agregados miúdos classificados como areia média apresentaram maiores valores de aderência do que os produzidos com areia fina. Ambos trabalhos concluíram também que, além da influência da areia, as características do substrato são muito relevantes para a aderência. Na mesma linha de raciocínio, o trabalho [36] demonstrou que revestimentos de argamassa com areia fina apresentaram resultados de aderência até $20 \%$ superiores do que os revestimentos produzidos com areia muito fina. Ademais, alguns autores [99] ressaltam que com o aumento do teor de areia há uma redução de resistência de aderência e que areias grossas não são muito adequadas para revestimentos, pois reduzem a extensão de aderência uma vez que afetam a trabalhabilidade (reologia) das argamassas. Quanto à espessura dos revestimentos, um dos estudos [14] variou entre 5 e $25 \mathrm{~mm}$ esta dimensão. Generalizando as situações, entretanto mantendo fixas as condições do substrato, tipo de argamassa utilizada e condições de exposição das alvenarias (orientação norte e sul), foi possível notar que com o aumento da espessura há redução dos valores de resistência de aderência do revestimento. De maneira parecida, em [53] os revestimentos de argamassa industrializada obtiveram resistências de aderência decrescentes à medida que a espessura aumentou nos substratos secos; o umedecimento no momento da aplicação da argamassa inverteu esta tendência, mas diminuiu os valores médios de aderência.

Muitos estudos utilizaram aditivos e/ou adições visando avaliar a influência desses materiais na aderência. Confrontando por valores médios, os resultados de resistência de aderência na incorporação dos aditivos ou adições com as argamassas de referência dos próprios trabalhos, foram obtidos os resultados de influência na aderência com respectiva variação total entre médias (média do revestimento com adição/aditivo e média da referência) apresentados na Tabela VI. No trabalho [47] duas argamassas com aditivo incorporador de ar (dosagem de $0,015 \% \mathrm{MC}$ ) obtiveram médias superiores quando comparadas com a de referência. Porém, as demais dosagens (acima de 0,2\% MC) utilizadas apresentaram resultados insatisfatórios, quando comparadas com os requisitos normativos vigentes à época e com a argamassa de referência. Vários autores, citados em [99], observaram que o uso de aditivo incorporador de ar de fato reduz a aderência. Mas o efeito é mais notado quando as argamassas possuem baixos teores de cimento ou são aplicadas sobre substratos com alta sucção de água. O entendimento atual, segundo [121], é que o ar incorporado em altos teores, geralmente acima de $20 \%$, pode representar problemas para os revestimentos, levando a descolamentos; no entanto, abaixo desse valor crítico, o ar incorporado até melhora a aderência, devido ao ganho na trabalhabilidade da argamassa, que permite 'molhar' melhor a superfície do substrato, resultando em um aumento na extensão da ligação. Alguns autores encontraram influência negativa na aderência quando do emprego de aditivo impermeabilizante nas argamassas, em todos casos estudados quando não houve cura das 
Tabela VI - Presença de adições/aditivos nas argamassas cimentícias dos estudos.

[Table VI - Presence of additions/additives in the cementitious mortars of the studies.]

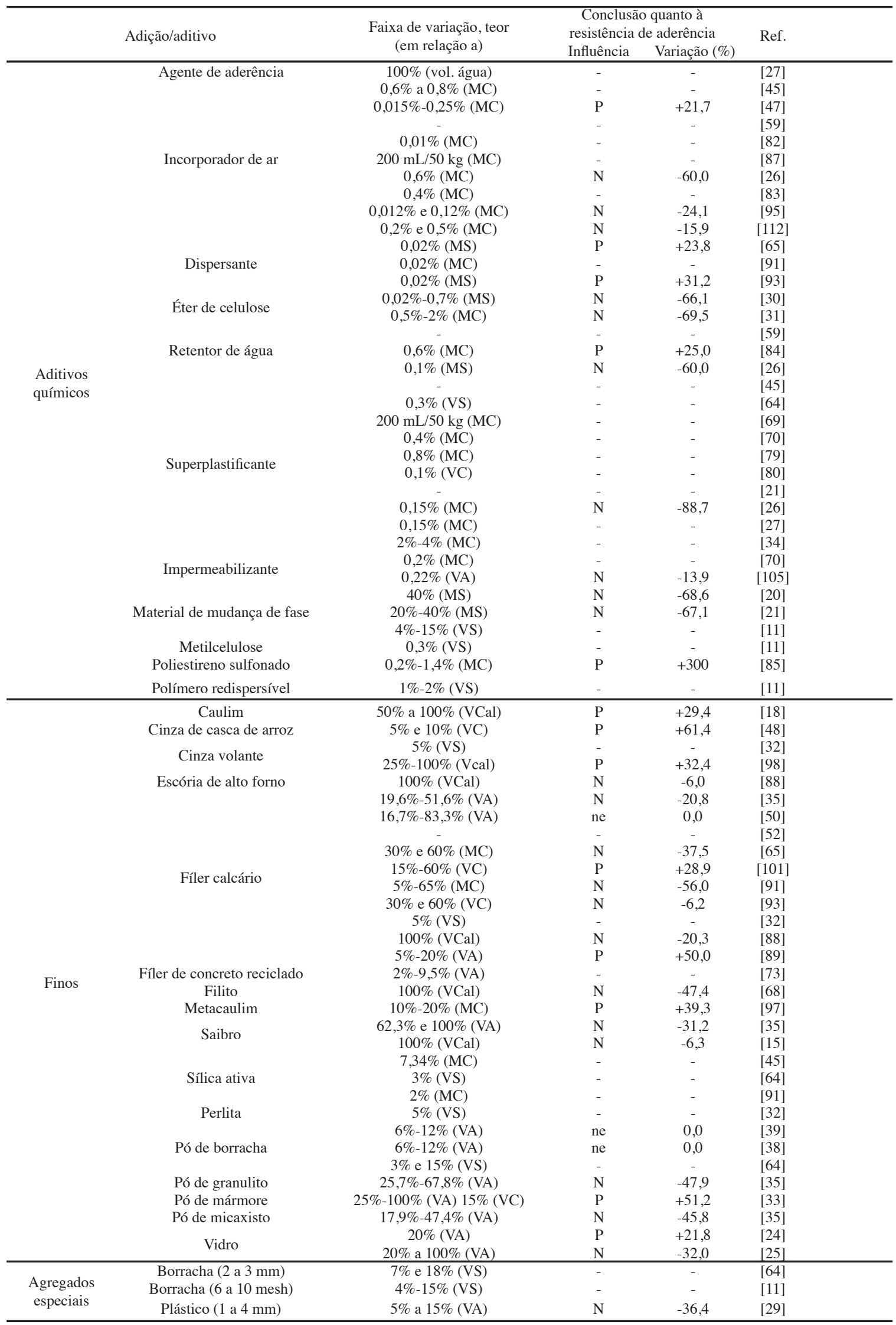

MC - massa cimento; MS - massa sólidos; VC - volume cimento; VS - volume sólidos; VCal - volume cal; VA - volume agregados; $N$ - influência negativa;

$P$ - influência positiva; ne - não exerce influência. 
argamassas. Entretanto, demonstraram um ganho de resistência de aderência (38,3\%) somente quando os revestimentos foram curados e projetados mecanicamente [105].

A substituição do aglomerante (cimento) por fíler calcário em até $30 \%$ não alterou a aderência [50, 65, 93]. Já Costa et al. [101] conseguiram valores de 0,49 MPa com adição de $15 \%$ de finos calcários, mas a aderência caiu até 53\% em argamassas com teores de $60 \%$ de finos. Apesar do valor médio global em [89] ser menor que dos demais autores, na substituição de agregado miúdo por fino calcário até $20 \%$ houve melhora gradativa dos valores de aderência à tração. Os resultados em [32, 88] serviram apenas nestes trabalhos para atestar a média global uma vez que não foram variados os teores de fíler (a porcentagem no proporcionamento da argamassa deste fino foi fixa). De acordo com [35], no qual foram utilizadas quatro adições diferentes (fíler calcário, saibro, pó de granulito e de micaxisto), em todos os teores de todas adições analisados, a resistência de aderência foi menor que a argamassa de referência sem adições, podendo ter relação com o aumento de fissuras por retração. Apesar disso, a adição de finos aumenta significativamente a trabalhabilidade das argamassas. Não foi possível atestar sobre a influência pelo uso de cinza volante e perlita (espécie de vidro vulcânico) na resistência de aderência no trabalho [32] que trata do uso destas adições, cujos teores não foram variados e não havia argamassa de referência (sem adições) para comparação. Contudo, segundo o artigo [98], a substituição em volume de $75 \%$ de cal por cinza volante levou a um aumento de $32 \%$ na resistência de aderência em relação à argamassa de referência sem adição. Verificou-se que substituições de areia por pó de mármore em até $50 \%$ foram benéficas para a aderência; acima deste valor houve decréscimo de resistência [33].

Material de mudança de fase (phase change material - PCM) é uma adição normalmente usada encapsulada que possui capacidade de alterar seu próprio estado físico em função da temperatura ambiente, contribuindo, por exemplo, para o desempenho térmico do revestimento. A sua utilização em $[20,21]$ e em temperatura ambiente demonstrou redução relativa nos valores de aderência ao substrato em todos os casos estudados (variando o tipo de aglomerante), tendo o pior resultado relativo quando se utilizou argamassa à base de cimento e o pior resultado absoluto quando do uso de cal aérea. A substituição de areia por fino de vidro, segundo encontrado em [24], teve diferença estatisticamente nula (sem efeito), especialmente no traço 1:4, em volume, da argamassa simples. Já segundo [25], o pior desempenho foi encontrado com $50 \%$ de substituição por fino de vidro, conforme o valor relativo apresentado na Tabela VI. Revela-se que as argamassas são compostas dos mais variados tipos de materiais; em geral, as adições e aditivos alteram significativamente as propriedades das argamassas com enfoque especial à aderência, sendo, portanto, de suma importância entender as possíveis interações destes compostos nas argamassas.

Características da execução dos revestimentos: com relação aos revestimentos, dois aspectos interessantes observados são a forma de aplicação da argamassa de revestimentos aos substratos e a realização de cura úmida nos revestimentos consolidados. Nos trabalhos pesquisados foram encontradas várias formas de aplicação das argamassas de revestimento sobre os substratos. Na Tabela VII estão identificados os cinco diferentes métodos encontrados nos artigos aderentes, inclusive o moldado que é realizado em aros com o objetivo de eliminar a necessidade de corte posterior dos corpos de prova. Dualibe et al. [105] compararam a aplicação manual com a projeção mecanizada e

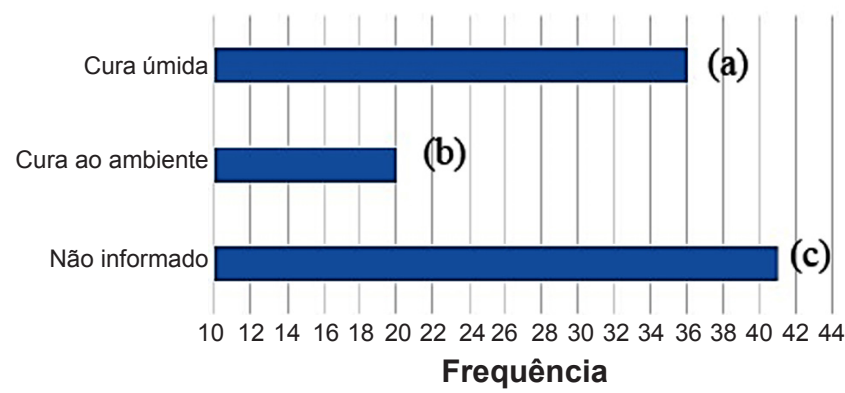

Figura 5: Frequências de cura úmida nos revestimentos. Refs.: a) $[19,22,23,25,28,30,33,35,36,40,42,49,51,52,55,58,64$, 67-71, 73, 76, 78, 82, 84, 86, 88, 91-93, 102, 105, 107, 112]; b) [13, $15,21,37,46,48,52,54,55,61,62,66,75,77,85,89,101,105$, $108,109]$; e c) $[11,12,14,16-18,20,24,26,27,29,31,32,34,38$, $39,41,43-45,47,50,53,56,57,59,60,63,72,74,79-81,83,87$, 90, 94-98, 106].

[Figure 5: Wet curing frequencies in renderings.]

Tabela VII - Formas de aplicação dos revestimentos.

[Table VII - Ways of applying renderings.]

\begin{tabular}{cc}
\hline Método & Ref. \\
\hline Lançamento manual & {$[12,14-17,23,27,28,35-37,41-46,50,52-59,61$,} \\
Caixa de queda & $62,67,73-75,77,79,81,83,86,94,105,108]$ \\
Moldados (corpos de prova) & {$[40,51,71,76,78,82,109,112]$} \\
Projeção mecânica & {$[20,33,64,65,91,93,95,101]$} \\
Desempenadeira & {$[41,75,81,87,92,102,105]$} \\
\hline
\end{tabular}


Tabela VIII - Faixas de coeficientes de variação obtidos no ensaio de aderência.

[Table VIII - Range of coefficients of variation of the bond test.]

\begin{tabular}{|c|c|c|c|}
\hline $\begin{array}{l}\text { Faixa de } \\
\text { CV }(\%) \\
\end{array}$ & $\begin{array}{c}\text { Tamanho da } \\
\text { amostra }\end{array}$ & $\begin{array}{l}\text { Revestimento considerado nesta análise } \\
\text { (confome informado pelos autores) }\end{array}$ & Ref. \\
\hline \multirow{6}{*}{$3-10$} & - & Mista: $\arg . \mathrm{N}^{\circ} 1$ & {$[56]^{*}$} \\
\hline & 6 & Simples: resíduo & [59]* \\
\hline & 18 & Mista: areia artificial & [72] \\
\hline & - & Simples: CPV & [84] \\
\hline & 3 & Simples: todas superfícies & [13] \\
\hline & - & Mista: média de todos cenários & [109] \\
\hline \multirow{14}{*}{$10-20$} & - & Simples: M0 0 & [89] (obra) \\
\hline & - & Mista: $\arg . \mathrm{N}^{\circ} 2$ & {$[56]^{*}$} \\
\hline & 6 & Industrializada: referência & [59]* \\
\hline & 24 & Mista: média substratos & {$[62]^{*}$} \\
\hline & - & Industrializada: com lavagem e escovagem & {$[67]$} \\
\hline & 16 & Mista: areia natural altura de queda $100 \mathrm{~cm}$ & [71] \\
\hline & 18 & Mista: adição finos 2\% & [73] \\
\hline & 12 & Mista: superfície lisa & [76] \\
\hline & - & Industrializada: média geral & [78] \\
\hline & - & Simples: referência & [22] \\
\hline & - & Simples: referências 1:4 e 1:5 & [24] \\
\hline & 15 & Simples: $\mathrm{C} 1$ sem aditivo & [95] \\
\hline & 4 & Rendering & [110] (laboratório) \\
\hline & 12 & Mista: referência em superfície lisa & [112] \\
\hline \multirow{10}{*}{$20-30$} & - & Mista: areia natural & {$[88]$} \\
\hline & 48 & Mista: com chapisco & [53] \\
\hline & 24 & Industrializada: média substratos & {$[62]^{*}$} \\
\hline & 8 & Simples: ref sem aditivo & {$[65]$} \\
\hline & 17 & Industrializada: projetado & {$[75]^{*}$} \\
\hline & 102 & Maior CV de todos eventos & [77] \\
\hline & 17 & Mista: bloco tipo 'B' & [17] \\
\hline & 5 & Simples: referência & {$[28]$} \\
\hline & 30 & Simples: referência & [91] \\
\hline & 20 & Simples: referência & [93] \\
\hline \multirow{9}{*}{$30-40$} & - & Simples: areia natural com fíler calcário & [88] \\
\hline & - & Simples: 28 dias chapisco 1:3 (cura) & [69] (obra) \\
\hline & 12 & Simples: família 1 & [74] \\
\hline & 17 & Industrializada: manual & {$[75]^{*}$} \\
\hline & $22 / 36$ & Mista: substrato placa de concreto e bloco tipo 'A' & [17] \\
\hline & 3 & Referência A0 & [23] \\
\hline & 30 & Industrializada: seção circular $50 \mathrm{~mm}$ & [102] \\
\hline & 18 & Simples: referência $0 \%$ & [101] \\
\hline & 181 & Industrializada: bloco cerâmico 28 dias & [108] \\
\hline \multirow{6}{*}{$40-50$} & 96 & $\begin{array}{l}\text { Revestimento aplicado em local sem manifestações } \\
\text { patológicas }\end{array}$ & [41] (obra) \\
\hline & 112 & Média sem chapisco & [53] \\
\hline & - & Média dos tipos de argamassa, interna & [63] (obra) \\
\hline & 30 & Industrializada: tipos de equipamentos A e B & [92] \\
\hline & 48 & Aplicacão manual & [105] \\
\hline & 210 & Industrializada: bloco de concreto 28 dias & [108] \\
\hline \multirow{5}{*}{$50-60$} & 24 & Média de CVs dos operadores L e R & [43] \\
\hline & 90 & Parede-referência & [44] \\
\hline & - & Média dos tipos de argamassa, externa & [63] (obra) \\
\hline & 21 & Casos C e D (seção quadrada) & [106] (obra)* \\
\hline & 210 & Industrializada: bloco de concreto 28 dias & [108] \\
\hline \multirow{2}{*}{$60-70$} & - & Simples: F0 & {$[79]$} \\
\hline & 116 & Rendering & [110] (obra) \\
\hline $70-80$ & 6 & Mista: referência sem chapisco & {$[82]$} \\
\hline
\end{tabular}


encontraram em média resultados $55 \%$ menores nos revestimentos aplicados manualmente; esta redução foi especialmente notada quando o teor de ar incorporado da argamassa é maior. Da mesma maneira, outro trabalho [75] comparou estas duas formas de aplicação e encontrou também valores menores de resistência de aderência nos revestimentos lançados de forma manual (30\% menor); ademais, é interessante destacar que a dispersão dos resultados foi maior no painel onde a argamassa foi lançada manualmente $(\mathrm{CV}=40 \%)$ em comparação com o painel onde a argamassa foi projetada mecanicamente $(\mathrm{CV}=21 \%)$. Foi demonstrado que a projeção mecânica apresenta, em média, maiores valores de aderência $(0,40 \mathrm{MPa})$ em relação a revestimentos aplicados com desempenadeira $(0,34 \mathrm{MPa})$ e aplicação manual $(0,28$ $\mathrm{MPa})$ [81].

$\mathrm{Na}$ Fig. 5 está apresentado o levantamento quanto à realização de cura úmida dos revestimentos que seriam testados, se considerados no escopo da pesquisa. Não foram encontradas informações a respeito de aplicação de curas química ou térmica nos trabalhos analisados. Associou-se a realização de cura úmida nos revestimentos com o aumento da aderência, muito embora tenham constatado também uma dependência dos resultados com o tipo de preparo do substrato [55].

Características dos testes de aderência à tração: os ensaios de resistência de aderência à tração podem ser realizados in loco, ou seja, em obra, ou em ambiente de laboratório. Doze autores realizaram os testes em obras (in loco) $[14,41,44,45,60,63,69,74,75,81,87,89$, $96,97,105,106,110]$. A grande maioria dos trabalhos analisados foi realizada em ambientes laboratoriais [11$13,15,17-40,42,43,46,48-54,56-59,61,62,65-67$, 70-73, 76-86, 88, 90-93, 95, 98, 102, 107-110, 112]. Nos trabalhos [81, 110] realizaram-se testes nas duas condições e chegaram a valores médios de 0,26 e 0,28 $\mathrm{MPa}$ (em campo) e 0,46 e 0,55 MPa (laboratório), nos mesmos tipos de substratos, respectivamente. Neste contexto, aproveitando a similaridade dos estudos, observando os mesmos traços com diferença básica apenas do local de realização dos ensaios (laboratório e em campo), foram obtidos os valores de 0,33 e 0,21 $\mathrm{MPa}$ em [88, 89], respectivamente. Por todo este exposto, demonstra-se que o ambiente de laboratório é fator relevante na maior média de aderência dado o maior controle de aplicação dos revestimentos e de realização dos ensaios. Outra análise importante no que diz respeito ao teste de aderência à tração é sobre resultados dos coeficientes de variação (CVs). A Tabela VIII apresenta as faixas de variação deste coeficiente para as argamassas de referência dos artigos que possibilitaram seu cálculo, onde o menor valor encontrado foi em [84] (3,3\%, nada comum) e o maior em [110] (67\%), este último de resultados obtidos em obra.

Requisitos mínimos técnico-normativos para aderência em revestimentos de argamassa: existem alguns documentos técnico-normativos que versam sobre requisitos mínimos de aderência que os revestimentos devem atender para serem considerados conformes. Foram encontrados nos trabalhos selecionados quatro destes documentos com requisitos sintetizados na Tabela IX. Também foram relacionados quantos trabalhos, dos 98 analisados (exceto [99, 100, 104, 111]), encontraram valores de aderência, considerando todas variações propostas, abaixo das recomendações. Apenas 10 $[12,22,27,31,33,76,85,94,95,112]$ dos 98 estudos $(10 \%)$ obtiveram valores que atendem, com todas as argamassas testadas, o maior limite normativo para aderência à tração $(0,60 \mathrm{MPa})$. Esta informação, aliada ao que foi exposto em $[63,110]$ com dados de diversas obras que sequer alcançaram $0,20 \mathrm{MPa}$ de média em aderência, comprova e alerta para o fato de que o estudo desta propriedade deve ser sempre levado em consideração, visto que negligenciar o controle de suas variáveis intervenientes pode trazer um grande risco à integridade das construções e até mesmo à segurança dos usuários destas. Ademais, cabem também estudos de revisão dos limites prescritos uma vez que fica demonstrado que os critérios estão superdimensionados com as realidades de resultados de testes em laboratório e em campo, mas é

Tabela IX - Critérios e valores mínimos normativos de resistência de aderência.

[Table IX - Criteria and minimum technical-normative values of adhesion strength.]

\begin{tabular}{|c|c|c|c|c|}
\hline Documento & \multicolumn{3}{|c|}{ Critérios e valores mínimos de aderência (MPa) } & $\begin{array}{c}\text { Qtd. artigos que encontraram } \\
\text { valores menores }\end{array}$ \\
\hline \multirow{5}{*}{ NBR 13749 [122] } & \multirow{2}{*}{ Parede interna } & Pintura ou base reboco & 0,20 & 57 \\
\hline & & Cerâmica ou laminado & 0,30 & \\
\hline & \multirow{2}{*}{ Parede externa } & Pintura ou base reboco & 0,30 & 76 \\
\hline & & Cerâmica & 0,30 & \\
\hline & Teto & Pintura ou base reboco & 0,20 & 57 \\
\hline \multirow{2}{*}{ NFP 15-201-1 [123] } & \multicolumn{2}{|c|}{ Substrato com média resistência de aderência } & 0,60 & 88 \\
\hline & \multicolumn{2}{|c|}{ Substrato com baixa resistência de aderência } & 0,40 & 82 \\
\hline $\begin{array}{c}\text { Normativas cubanas, } \\
\text { citadas em }[88,89]\end{array}$ & \multicolumn{3}{|c|}{0,20} & 57 \\
\hline
\end{tabular}




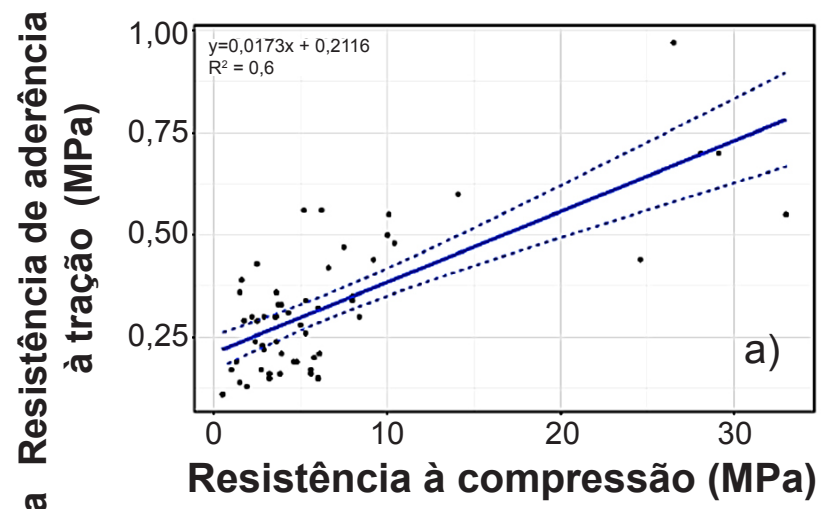

正

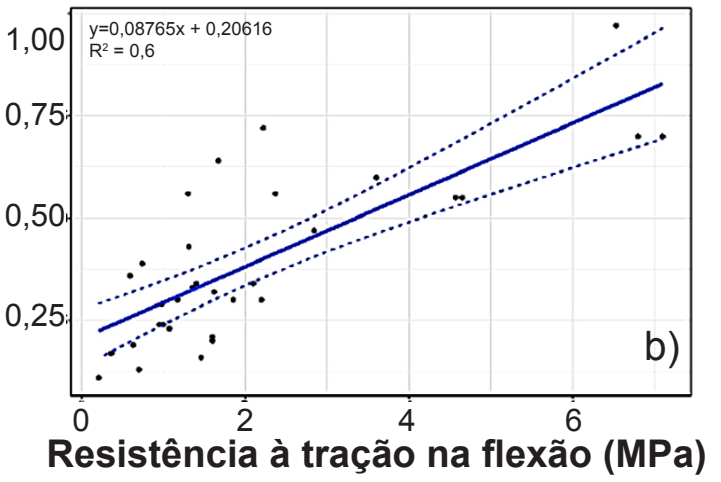

Figura 6: Linhas de tendência com respectivo intervalo de confiança (95\%) entre resistência de aderência e: a) resistência à compressão; e b) resistência à tração na flexão.

[Figure 6: Trend lines with respective confidence interval (95\%) between bond strength and: a) compression strength; and b) flexural tensile strength.]

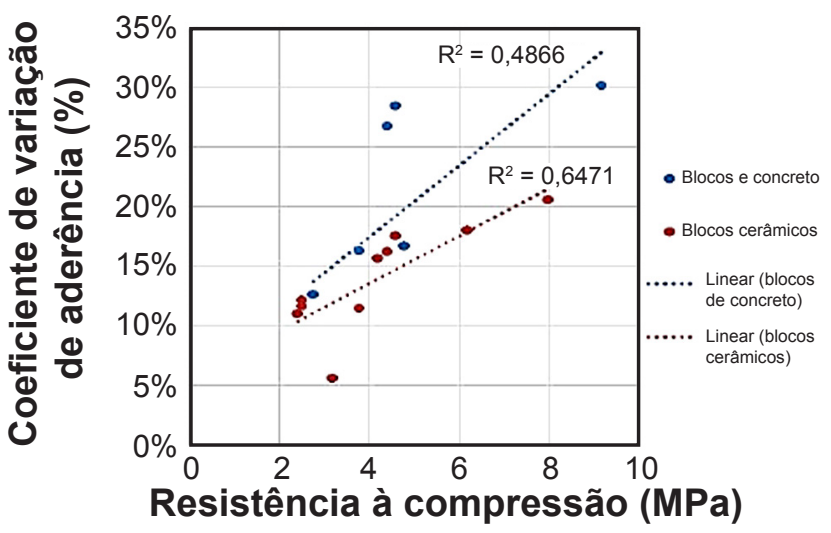

Figura 7: Linhas de tendências entre resistências à compressão das argamassas e coeficientes de variação da resistência de aderência. [Figure 7: Trend lines between compressive strengths of mortars and coefficients of variation of bond strength.]

impossível, pela estrita análise dos dados destes estudo, fixar novos valores de referência, pois dependem de estudos em campo que atestem a segurança necessária, inclusive a longo prazo, dos revestimentos de argamassa e pinturas, laminados, cerâmicas, entre outros que são aderidos a estes revestimentos.

Correlações com resistência à compressão e à tração na flexão: tendo em vista que as propriedades das argamassas mais caracterizadas nos artigos estudados foram as resistências à compressão e à tração na flexão, foram feitas tentativas de correlação entre estas resistências com a de aderência à tração. Independentemente do tipo e composição das argamassas e substratos, a Fig. 6a apresenta os dados de 60 trabalhos relevantes a esta revisão (56 após análise de espúrios) que disponibilizaram o par ordenado (resistência à compressão, resistência de aderência à tração) para argamassas sem adições ou aditivos. Após, o mesmo foi realizado para correlacionar com a resistência à tração na flexão, conforme apresentado na Fig. 6b. É possível notar que se chegou a dois coeficientes de determinação $\left(\mathrm{R}^{2}\right)$ aceitáveis estatisticamente de 0,55 e 0,61 .

Uma forma interessante para apresentação de resultados é uma relação da resistência à compressão das argamassas com os coeficientes de variação da resistência de aderência. De forma a melhorar ainda mais essa apresentação foram marcados os tipos de substratos usados em cada estudo (Fig. 7). Foram encontrados coeficientes de determinação de 0,5 para blocos de concreto e 0,6 quando os substratos são de blocos cerâmicos. Infelizmente pela quantidade pequena de dados disponíveis nos trabalhos obtidos no levantamento não foi possível concluir que de fato existam correlações fortes baseadas no substrato, ou seja, que sejam os determinantes da correlação linear entre estas duas variáveis.

\section{CONCLUSÕES}

Este mapeamento com revisão sistemática de literatura alcançou os objetivos de levantar e organizar os trabalhos relativos à resistência de aderência à tração de revestimentos de argamassa de maneira a facilitar e fomentar as análises de literatura de futuros trabalhos no tema em questão. Abordando apenas trabalhos publicados em periódicos e eventos científicos da área, foram obtidos resultados relevantes. Podem ser listadas como principais conclusões do levantamento: i) há uma forte tendência de aumento nos estudos com ênfase na aderência de revestimentos de argamassa e consequente publicação em periódicos de alcance internacional, com crescimento observado principalmente nos últimos cinco anos, inclusive com aceitação em periódicos com altos fatores de impacto; ii) as normas utilizadas para determinação da resistência de aderência à tração são basicamente a europeia EN 1015-12 e a brasileira NBR 13528, demonstrando que a produção científica na área se concentra nos países em que existe a predominância de emprego de sistemas de vedação revestidos com argamassa, tais como França, Portugal, Espanha, Alemanha, além do Brasil; iii) os substratos mais utilizados nas pesquisas são compostos por blocos cerâmicos e blocos de concreto, sendo que os revestimentos aplicados sobre blocos de concreto apresentam geralmente maior resistência de aderência que sobre os blocos cerâmicos 
(cerca de $32 \%$ menor); iv) a composição das argamassas utilizadas nas pesquisas sobre aderência é bastante variada, seja quanto aos traços (proporcionamentos) ou aos materiais empregados; isto faz com que essa variável seja uma das mais influentes nos resultados de resistência de aderência dos revestimentos, cujos valores dos coeficientes de variação, relativos a essa diversidade de composições, se demonstraram demasiadamente altos, principalmente nas composições mais pobres em cimento; v) em geral, o uso de aditivos e adições nas argamassas alteram o comportamento da aderência, podendo tanto melhorar quanto piorar o desempenho dos revestimentos; o uso de éter de celulose e material de mudança de fase, por exemplo, foram os que mais negativamente influenciaram na resistência (68\% de perda em aderência com relação às respectivas referências); vi) a forma de aplicação da argamassa, a realização ou não de cura úmida e o local de realização dos ensaios (em campo ou em laboratório) exercem influências significativas nos resultados de aderência dos revestimentos; a projeção mecânica apresentou as maiores médias de aderência e menores coeficientes de variação; revestimentos que passaram por processo de cura úmida e testes executados em laboratório também apresentaram as maiores médias quando comparadas a revestimentos sem cura úmida e com testes em campo; vii) ainda há o que se estudar no que diz respeito aos coeficientes de variação dos resultados dos ensaios de aderência à tração, principalmente se há diferença significativa, do ponto de vista estatístico, entre testes realizados em obra e em laboratório; viii) existe razoável correlação entre as resistências de aderência à tração dos revestimentos e as resistências à compressão axial ou à tração na flexão das argamassas, independentemente da composição dessas argamassas, subsidiando futuros estudos com mais dados; ix) há uma interdependência moderada entre a resistência à compressão das argamassas e os coeficientes de variação de aderência dos revestimentos aplicados, por tipo de substrato; e x) sugere-se que futuros estudos empreguem um menor número de trabalhos (mantendo um universo de resultados compatível com a quantidade de variáveis controladas) que traga resultados mais concisos nas variáveis mais preponderantes destacadas neste artigo, que possibilita focalizar os esforços e análises, de modo a precisar estatisticamente os graus de influências de cada fator na resistência de aderência.

\section{AGRADECIMENTO}

Os autores agradecem à FAPEG - Fundação de Amparo à Pesquisa do Estado de Goiás, pela bolsa de fomento científico.

\section{REFERÊNCIAS}

[1] ABNT, NBR 13528, "Revestimento de paredes e tetos de argamassas inorgânicas - determinação da resistência de aderência à tração", Rio Janeiro (2010).

[2] Eur. Comm. Stand., EN 1015-12 "Methods of test for mortar for masonry - part 12: determination of adhesive strength of hardened rendering and plastering mortars on substrates" (2016).

[3] ASTM Int., D4541 "Standard test method for pull-off strength of coatings using portable adhesion testers" (2009). [4] Inst. Belge Norm., NBN 813-05, "Essais des mortiers adhérence par arrachement" (1969).

[5] B. Kitchenham, "Guidelines for performing systematic literature reviews in software engineering", UK (2007).

[6] M. Niazi, Arab. J. Sci. Eng. 40 (2015) 845.

[7] M. Staples, M. Niazi, J. Syst. Softw. 80 (2007) 1425.

[8] B.N. Green, C.D. Johnson, A. Adams, J. Chiropr. Med. 5 (2006) 101.

[9] D. Tranfield, D. Denyer, P. Smart, Br. J. Manag. 14 (2003) 207.

[10] SCImago, "Scimago Journal \& Country Rank", https:// www.scimagojr.com/, ac. 01/03/2018.

[11] P. Meshgin, Y. Xi, Y. Li, Constr. Build. Mater. 28 (2012) 713.

[12] Ł. Sadowski, J. Hoła, S. Czarnecki, D. Wang, Autom. Constr. 85 (2018) 10.

[13] Ł. Sadowski, A. Żak, J. Hoła, Arch. Civ. Mech. Eng. 18 (2018) 573.

[14] H. Almeida Jr, I.J. Lopez, J.M. Martins, F.H. Sabbatini, in Anais I Simp. Bras. Tecnol. Argamas., Goiânia (1995) 236.

[15] H. Carasek, O. Cascudo, P.F. Santos, in Anais I Simp. Bras. Tecnol. Argamas., Goiânia (1995) 247.

[16] A.N. Carvalho Jr, A.P. Silva, E.P. França, in Anais I Simp. Bras. Tecnol. Argamas., Goiânia (1995) 261.

[17] P.R. Ioppi, L.R. Prudêncio, W.J. Iriyama, in Anais I Simp. Bras. Tecnol. Argamas., Goiânia (1995) 93.

[18] C. Neves, A.H. Almeida, A. Gomes, W. Ruas Jr, in Anais I Simp. Bras. Tecnol. Argamas., Goiânia (1995) 219.

[19] M. Braga, J. de Brito, R. Veiga, Constr. Build. Mater. 36 (2012) 960.

[20] S. Cunha, J. Aguiar, V. Ferreira, A. Tadeu, Rev. Matér. 20 (2015) 245.

[21] S. Cunha, J. Aguiar, F. Pacheco-Torgal, Constr. Build. Mater. 98 (2015) 89.

[22] J. Lucas, J. de Brito, R. Veiga, C. Farinha, Mater. Des. 91 (2016) 155.

[23] C. Neno, J. de Brito, R. Veiga, Mater. Res. 17 (2014) 168.

[24] R. Oliveira, J. de Brito, R. Veiga, J. Clean. Prod. 95 (2015) 75.

[25] P. Penacho, J. de Brito, M. Rosário Veiga, Cem. Concr. Compos. 50 (2014) 47.

[26] I. Santamaría-Vicario, A. Rodríguez, S. GutiérrezGonzález, V. Calderón, Constr. Build. Mater. 95 (2015) 197.

[27] T. Sevil, M. Baran, T. Bilir, E. Canbay, Constr. Build. Mater. 25 (2011) 892.

[28] J. Silva, J. de Brito, R. Veiga, Constr. Build. Mater. 23 (2009) 556.

[29] A.M. da Silva, J. de Brito, R. Veiga, Constr. Build. Mater. 71 (2014) 226.

[30] E. Spychał, Procedia Eng. 108 (2015) 324. 
[31] E. Jumate, D.L. Manea, C. Aciu, L. Molnar, R. Fechete, Procedia Technol. 19 (2015) 291.

[32] M. Katsioti, D. Gkanis, P. Pipilikaki, A. Sakellariou, A. Papathanasiou, C. Teas, E. Chaniotakis, P. Moundoulas, A. Moropoulou, Constr. Build. Mater. 23 (2009) 1960.

[33] L.M. Molnar, D.L. Manea, Procedia Technol. 22 (2016) 251.

[34] P. Saiz-Martínez, M. González-Cortina, F. FernándezMartínez, Mater. Constr. 65 (2015) e058.

[35] R.R. Angelim, S.C.M. Angelim, H. Carasek, in Anais V Simp. Bras. Tecnol. Argamas., S. Paulo (2003) 401.

[36] R.R. Angelim, S.C.M. Angelim, H. Carasek, in Anais V Simp. Bras. Tecnol. Argamas., S. Paulo (2003) 159.

[37] H. Bolorino, M.A. Cincotto, in Anais II Simp. Bras. Tecnol. Argamas., Salvador (1997) 15.

[38] J.A. Canova, R. Bergamasco, G. Angelis Neto, P.J.P. Gleize, Amb. Constr. 12 (2012) 257.

[39] J.A. Canova, R. Bergamasco, G. Angelis Neto, Acta Sci. Technol. 29 (2007) 141.

[40] H. Carasek, in Anais II Simp. Bras. Tecnol. Argamas., Salvador (1997) 133.

[41] H. Carasek, O. Cascudo, T.R. Jucá, in Anais VI Simp. Bras. Tecnol. Argamas., Florian. (2005) 551.

[42] H. Carasek, L.M. Scartezini, in Anais III Simp. Bras. Tecnol. Argamas., Vitória (1999) 503.

[43] E.B.C. Costa, R.J. Duarte, H. Carasek, in Anais Enc. Nac. Tecnol. Amb. Const., Florian. (2006) 4061.

[44] S.R.C. Gonçalves, E. Bauer, in Anais VI Simp. Bras. Tecnol. Argamas., Florian. (2005) 562.

[45] D. Macedo, P. Ribeiro, G. Machado, H. Carasek, O. Cascudo, in Anais VII Simp. Bras. Tecnol. Argamas., Recife (2007).

[46] L.F.R. Miranda, S.M.S. Selmo, Constr. Build. Mater. 20 (2006) 625.

[47] R. Monte, K.L. Uemoto, S.M.S. Selmo, in Anais V Simp. Bras. Tecnol. Argamas., S. Paulo (2003) 303.

[48] C.A.M. Moraes, A.G. Kieling, M.O. Caetano, L.P. Gomes, Resour. Conserv. Recycl. 54 (2010) 1170.

[49] C.B. Moura, L.C. Bonin, A.B. Masuero, in Anais VIII Simp. Bras. Tecnol. Argamas., Curitiba (2009) 1.

[50] I.L. Paes, M.A.S. Andrade, R.R. Angelim, N.P. Hasparyk, R.A. Oliveira, J.S. Passos, D.G. Thon, H. Carasek, in Anais III Simp. Bras. Tecnol. Argamas., Vitória (1999) 335.

[51] D.T. Pagnussat, A.B. Masuero, in Anais IX Simp. Bras. Tecnol. Argamas., Belo Horizonte (2011).

[52] P.C. Pereira, J.A. Ikeda, N.A. Ikeda, C.O. Campos, L.M. Teixeira, H. Carasek, in Anais III Simp. Bras. Tecnol. Argamas., Vitória (1999).

[53] L.R. Prudêncio, W.O. Isernhagen, R.O. Steil, M.R. Macarini, in Anais III Simp. Bras. Tecnol. Argamas., Vitória (1999) 453.

[54] L.M. Scartezini, T.R. Jucá, H. Linhares, F. Teixeira, G. Antonelli, O. Cascudo, H. Carasek, Amb. Constr. 2 (2002) 85.

[55] L.M. Scartezini, H. Carasek, in Anais V Simp. Bras. Tecnol. Argamas., S. Paulo (2003) 569.
[56] N.G. Silva, V.C. Campiteli, P.J.P. Gleize, in Anais VII Simp. Bras. Tecnol. Argamas., Recife (2007).

[57] N.G. Silva, V.C. Campiteli, P.J.P. Gleize, in Anais VII Simp. Bras. Tecnol. Argamas., Recife (2007).

[58] V.S. Silva, J.B.L. Libório, in Anais V Simp. Bras. Tecnol. Argamas., S. Paulo (2003) 385.

[59] N.G. Silva, G.G. Silva, P.J.P. Gleize, in Anais X Simp. Bras. Tecnol. Argamas., Fortaleza (2013) 1.

[60] A.S.R. Silva, A.F. Silva Filho, M.T. Azevedo, L.V. Garcia, E.G. Mattos, in Anais II Simp. Bras. Tecnol. Argamas., Salvador (1997) 185.

[61] D.A. Silva, F.A. Tristão, H.R. Roman, F.K. Souza, in Anais V Simp. Bras. Tecnol. Argamas., S. Paulo (2003) 317. [62] C.R. Taube, G.P. Gava, S.M.F. Couri Petrauski, in Anais V Simp. Bras. Tecnol. Argamas., S. Paulo (2003) 221.

[63] H. Carasek, M. Malagoni, V. Terra, A.C.C. Girardi, R. Araújo, in Anais XII Simp. Bras. Tecnol. Argamas., S. Paulo (2017).

[64] C.L.D. Cintra, A.E.M. Paiva, J.B. Baldo, Cerâmica 60 (2014) 69.

[65] E.B.C. Costa, F.A. Cardoso, V.M. John, Constr. Build. Mater. 156 (2017) 1114.

[66] C.S. Kazmierczak, D.C.M. Arnold, Proc. Inst. Civ. Eng. Constr. Mater. 166 (2013) 27.

[67] P. Miotto, C.V. Silva, in Anais XII Simp. Bras. Tecnol. Argamas., S. Paulo (2017).

[68] T.F. de Oliveira, M.H. Beck, P.V. Escosteguy, E.C. Bortoluzzi, M.L. Modolo, Appl. Clay Sci. 105-106 (2015) 113.

[69] I.L. Paes, C. Silva, B. Campos, G. Evangelista, L. Ribeiro, E. Ribeiro, in Anais XII Simp. Bras. Tecnol. Argamas., S. Paulo (2017).

[70] A.L.F. Ramos, I.S.G. Freitas, P.B. Silveira, A.C.C. Lopes, M.V.O. Andrade, I.L. Paes, in Anais XII Simp. Bras. Tecnol. Argamas., S. Paulo (2017).

[71] A.B. Rohden, G.S. Lamb, M.L. Pinto, L.C. Bonin, A.B . Masuero, in Anais XIII Enc. Nac. Tecnol. Amb. Const., Canela (2010).

[72] W.J. dos Santos, R.C.S.S. Alvarenga, L.G. Pedroti, R.C. da Silva, A.S. Freire, B.A. de Moraes, C.C. Carvalho, Amb. Constr. 18 (2018) 225.

[73] J.A.A. Sentena, C.S. Kazmierczak, L.A. Krein, Amb. Constr. 18 (2018) 211.

[74] A.C.M. Silva, C. Santos, P. Rosal, R. Correa, A.J.C. Silva, in Anais XII Simp. Bras. Tecnol. Argamas., S. Paulo (2017).

[75] A.J.C. Silva, J.M.F. Mota, F.R. Barbosa, in Anais X Simp. Bras. Tecnol. Argamas., Fortaleza (2013).

[76] C.M. Stolz, D.T. Pagnussat, A.B. Masuero, A.P. Kirchheim, in Anais IX Simp. Bras. Tecnol. Argamas., Belo Horizonte (2011).

[77] A.L. Temp, G. Mohamad, E. Rizzatti, E.Y.N. Bavastri, in Anais X Simp. Bras. Tecnol. Argamas., Fortaleza (2013). [78] T.G. Tiggemann, M.A. Longhi, in Anais XII Simp. Bras. Tecnol. Argamas., S. Paulo (2017).

[79] B.L. Tiscoski, E.G.P. Antunes, M. Vito, D.S.S. Godinho, in Anais XII Simp. Bras. Tecnol. Argamas., S. Paulo (2017), 
[80] R.B. Tokarski, A. Matoski, L. Cechin, A.M. Weber, in Anais XII Simp. Bras. Tecnol. Argamas., S. Paulo (2017). [81] K.C. Zanelatto, M.M.S.B. Barros, R. Monte, F.H. Sabbatini, Amb. Constr. 13 (2013) 87.

[82] M.P. Assali, K. Loh, Amb. Constr. 11 (2011) 7.

[83] E. Bauer, C.P. Feitosa, H. Rodrigues Filho, P.O. Almeida, in Anais X Simp. Bras. Tecnol. Argamas., Fortaleza (2013). [84] S.F. da Cruz, J.G. Vieira, G. Rodrigues Filho, C.S. Meireles, F.A.C. Faria, D.D. Gomide, D. Pasquini, R.M.N. de Assunção, L.A.C. Motta, Polímeros 22 (2012) 80.

[85] L.A.C. Motta, J.G. Vieira, T.H. Omena, F.A.C. Faria, G. Rodrigues Filho, R.M.N. Assunção, Rev. Ibracon Estrut. Mater. 9 (2016) 754.

[86] R.P. Oliveira, A.L.G. Gastaldini, L.H. Antes, A.S. Ruviaro, in Anais XI Simp. Bras. Tecnol. Argamas., Porto Alegre (2015).

[87] L.C. Ruffeil, A.A. Silva, B.B. Grisolia, K.R. Fonseca, P.M. Rodrigues, C.V.S. Bordalo, I.N. Paes, in Anais XII Simp. Bras. Tecnol. Argamas., S. Paulo (2017).

[88] I. Martínez, M. Etxeberria, E. Pavón, N. Díaz, Constr. Build. Mater. 49 (2013) 384.

[89] I. Martínez, M. Etxeberria, E. Pavón, N. Díaz, Rev. Constr. 15 (2016) 9.

[90] R.R. Angelim, in Anais VI Simp. Bras. Tecnol. Argamas., Florian. (2005) 530.

[91] R. Berton, C.H.R. Magri, E.B.C. Costa, in Anais XII Simp. Bras. Tecnol. Argamas., S. Paulo (2017).

[92] E.B.C. Costa, H. Carasek, in Anais XII Enc. Nac. Tecnol. Amb. Const., Fortaleza (2008).

[93] E.B.C. Costa, F.A. Cardoso, V.M. John, Amb. Constr. 16 (2016) 21.

[94] M.L.C. Martins, A.A. Azevedo, in Anais IV Simp. Bras. Tecnol. Argamas., Brasília (2001) 499.

[95] R.C.O. Romano, D.R. Torres, R.G. Pileggi, Constr. Build. Mater. 82 (2015) 219.

[96] A.G. Diogenes, A.E.B. Cabral, in Anais XII Simp. Bras. Tecnol. Argamas., S. Paulo (2017).

[97] J.M.F. Mota, H. Carasek, A.J.C. Silva, F.R. Barbosa, A. Feitosa, W. Santos, in Anais IX Simp. Bras. Tecnol. Argamas., Belo Horizonte (2011).

[98] K.N.H. Sampaio, A.E.B. Cabral, in Anais XII Simp. Bras. Tecnol. Argamas., S. Paulo (2017).

[99] H. Carasek, O. Cascudo, L.M. Scartezini, in Anais IV Simp. Bras. Tecnol. Argamas., Brasília (2001) 43.

[100] E. Costa, H. Carasek, S. Almeida, D. Araújo, in Anais XIV Semin. Inic. Cient., Goiânia (2006).

[101] E.B.C. Costa, B.L. Damineli, V.B. Freitas, V.M. John, Rev. Ibracon Estrut. Mater. 8 (2015) 66.
[102] E.B.C. Costa, H. Carasek, Amb. Constr. 9 (2009) 17. [103] E. Costa, H. Carasek, in Anais VIII Simp. Bras. Tecnol. Argamas., Curitiba (2009).

[104] E.B.C. Costa, V.M. John, in Anais IX Simp. Bras. Tecnol. Argamas., Belo Horizonte (2011).

[105] R.P. Dualibe, G.R. Cavani, M.C.B. Oliveira, in Anais VI Simp. Bras. Tecnol. Argamas., Florian. (2005) 508.

[106] I. Flores-Colen, J. de Brito, F. Branco, Exp. Tech. 33 (2009) 51.

[107] C.S. Kazmierczak, D.E. Brezezinski, D. Collatto, in Anais VIII Simp. Bras. Tecnol. Argamas., Curitiba (2009).

[108] E. Nakakura, F.A.C. Munhoz, A. Battagin, in Anais VIII Simp. Bras. Tecnol. Argamas., Curitiba (2009).

[109] I.N. Paes, E. Bauer, H. Carasek, E. Pavón, Rev. Ing. Constr. 29 (2014) 175.

[110] N.M.M. Ramos, M.L. Simões, J.M.P.Q. Delgado, V.P. de Freitas, Constr. Build. Mater. 31 (2012) 86.

[111] R.V. Silva, J. de Brito, R.K. Dhir, Constr. Build. Mater. 105 (2016) 400.

[112] C.M. Stolz, A.B. Masuero, D.T. Pagnussat, A.P. Kirchheim, Constr. Build. Mater. 128 (2016) 298.

[113] Ofic. Nac. Normaliz., NC 172, "Resistencia a la adherencia por tracción”, Havana (2002).

[114] ASTM Int., D7234, "Standard test method for pulloff adhesion strength of coatings on concrete using portable pull-off adhesion testers" (2005).

[115] ABNT, NBR 15258, “Argamassa para revestimento de paredes e tetos - determinação da resistência potencial de aderência à tração", Rio Janeiro (2005).

[116] RILEM, Mater. Struct. 37 (2004) 488.

[117] L.M. Scartezini, H. Carasek, in Anais Cong. Bras. Cimento, S. Paulo (1999).

[118] C.F.A. Calado, A. Camões, S. Jalali, B. Barkokébas Jr, Concreto auto-adensável (CAA), mais do que alternativa ao concreto convencional (CC), Ed. Un. Pernambuco, Recife (2015).

[119] ABNT, NBR 7211, "Agregados para concreto", Rio Janeiro (1983).

[120] ABNT, NBR 7211 "Agregados para concreto especificação", Rio Janeiro (2009).

[121] H. Carasek, in Mater. Constr. Civ. Princ. Ciênc. Eng. Mater., G.C. Isaia (Ed.), S. Paulo (2017) 892.

[122] ABNT, NBR 13749, "Revestimento de paredes e tetos de argamassas inorgânicas - especificação", Rio Janeiro (2013).

[123] Ass. Franç. Normal., NFP 15-201-1, “Travaux d'enduits de mortiers - partie 1-1: cahier des clauses techniques" (2008).

(Rec. 20/06/2018, Rev. 21/12/2018, Ac. 23/01/2019) 